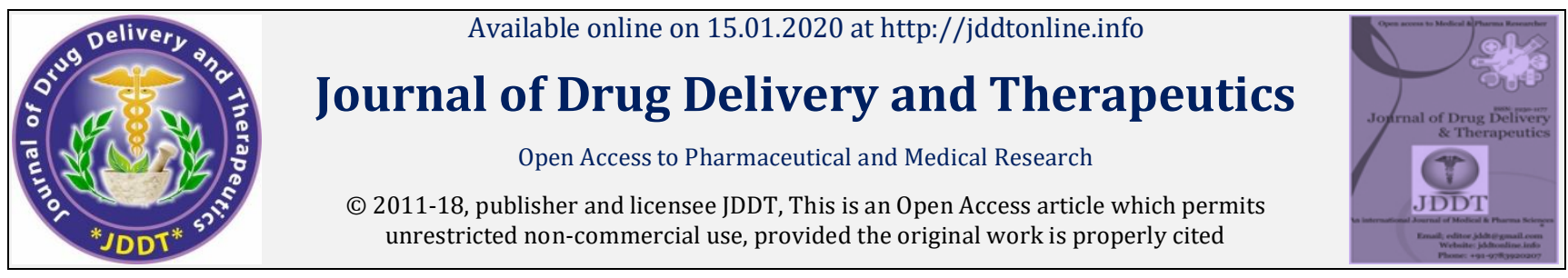

Open 2 Access

Research Article

\title{
In-Vitro Comparative Dissolution Study of Commercially Available Paracetamol Tablet
}

\author{
Kar Ayan Kumar*1,2, Kar Banhishikha1 \\ ${ }^{1}$ Department of Pharmaceutics, Calcutta Institute of Pharmaceutical Technology \& AHS, Banitabla, Uluberia, Howrah-711316, West Bengal \\ ${ }^{2}$ School of Pharmacy, Techno India University, Salt Lake, West Bengal
}

\begin{abstract}
Quality is the most important issue in the pharmaceutical field due to the presence of a drug which is considered as safe and therapeutically active agent. In-vitro evaluation ensures their quality, bioavailability as well as optimum therapeutic activity. Paracetamol (acetaminophen) which are the active metabolites of phenacetin is commonly used for the relief of headaches and pains, and is a major ingredient in numerous cold and flu remedies. Paracetamols are available in different brands in Indian market. The main objective of the present study was to conduct the comparative in-vitro dissolution studies of various brands collected from the local market to determine whether all the formulations used were equivalent or significantly different. The calibration curve was constructed covering the concentration range of 1 to $10 \mathrm{mcg} / \mathrm{ml}$ at $268 \mathrm{~nm}$ by UV spectrophotometer (UV 2203 Double beam spectrophotometer, Shimadzu). Five different brands of Paracetamol of 500 mg conventional tablets from different manufacturers were selected in the study and dissolution testing in Phosphate buffer at pH $7.4 \mathrm{was}$ conducted from each brands for 90 mins by using dissolution testing apparatus USP type-II. The dissolution rate was subjected to various mathematical models like zero order, first order, Higuchi and Hixson-Crowell equations to elucidate the kinetic behavior of drug release from the test samples. Different release kinetics model of all the selected brands was assuring the quality standard of manufacturing.
\end{abstract}

Keywords: Paracetamol, Marketed Tablet, In-Vitro dissolution study, Release profile.

Article Info: Received 18 Nov 2019; $\quad$ Review Completed 13 Dec 2019; $\quad$ Accepted 20 Dec 2019; Available online 15 Jan 2020

\section{Cite this article as:}

Kar AK, Kar B, In-Vitro Comparative Dissolution Study of Commercially Available Paracetamol Tablet, Journal of Drug Delivery and Therapeutics. 2020; 10(1):18-23 http://dx.doi.org/10.22270/jddt.v10i1.3817

*Address for Correspondence:

Kar Ayan Kumar, Department of Pharmaceutics, Calcutta Institute of Pharmaceutical Technology \& AHS, Banitabla, Uluberia, Howrah-711316, West Bengal

\section{INTRODUCTION:}

Oral dosage form like tablets, capsules, suspensions etc is one of the most common method used for the administration of drug.. Among all, tablets are more widely used being tempered free, cost effective, and stable. In formulation systems, manufacturing process and raw materials used affects the quality of finished product. It is very much essential to determine the parameters of tablets to ensure the quality of the product. Quality of the finished product depends upon the early developmental process. A tablet contains a drug molecule and excipients which are used mainly to maintain the physical parameters as well as to control the release of drug from its dosage from. For a single generic drug, various brands are available. Quality of all available brands needs to be assessed in order to provide an efficacious formulation, this responsibility increases in case of over the counter (OTC) medicines, quality of the product vary from manufacturer to manufacturer [1].
Paracetamol, a widely prescribed Non-steroidal antiinflammatory drug (NSAID) is used for the relief of pains associated with many parts of the body. Chemically, it is 4hydroxy acetanilide (acetaminophen) which belongs to the non-salicylate analgesic group. This drug which has wellestablished metabolic and pharmacokinetic $(\mathrm{pK})$ profiles is a universally accepted analgesic and antipyretic drug. It is poorly aqueous soluble and its frequency of administration is high due to low bioavailability [2,3].

Paracetamol has analgesic properties comparable to those of aspirin, while its anti-inflammatory effects are weaker. It is better tolerated than aspirin in patients in whom excessive gastric acid secretion or prolongation of bleeding time may be a concern. Available without a prescription, it has in recent years increasingly become a common household drug.[4] 


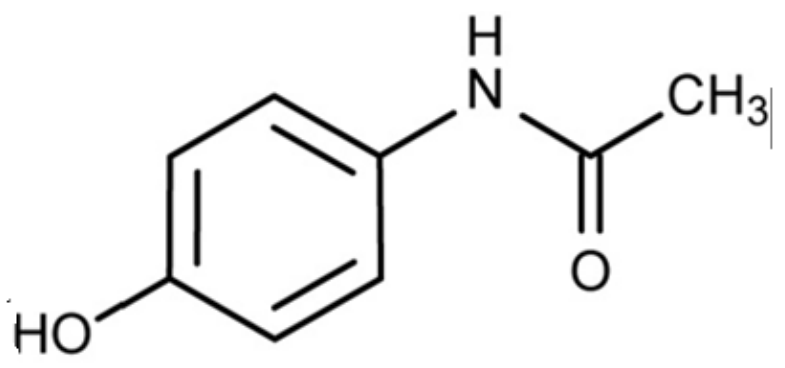

Fig. 1: Structure of Paracetamol [4]

Dissolution test, a qualitative and quantitative tool is one of the in vitro tests help to operate the quality of oral pharmaceutical solid dosage forms such as tablets and capsules. This test gives some important information about the biological availability of a drug and also batch to batch consistency of products [5].

The quality of marketed drugs determines the conditions of the patients treated. On the other hand, health condition of a consumer can be put at risk by the use of substandard drugs. So, continuous segregating process should be needed by the consumer organization for the awareness about the quality of drug available. Specially, some small and medium pharmaceutical industries do not analyse their drug or product properly before marketing due to the high expense for maintaining the quality control [6].

Therefore, it was decided to carry out the comparative evaluation of in vitro dissolution qualities of various commercially available paracetamol tablet samples. Paracetamol tablets of $500 \mathrm{mg}$ were chosen for the study. Statistical assessment of various in vitro dissolution parameters was conducted to establish if there were any significant differences among them.

\section{MATERIALS AND METHOD:}

Materials:- Paracetamol tablets (500 mg) were collected from the local market in west Bengal from the different company which is given in Table 1 . All other ingredients were taken as an analytical grade.

Table 1: List of collected marketed paracetamol tablet

\begin{tabular}{|l|l|l|l|l|c|}
\hline Sl. No. & Brand Name & Company Name & $\begin{array}{l}\text { Manufacturing } \\
\text { date }\end{array}$ & Expiry date & Batch code \\
\hline & Apex 500 & Apex Lab. Pvt Ltd & 24.01 .2019 & 28.11 .2021 & F - A \\
\hline & Crocin 500 & $\begin{array}{l}\text { Remidex Pharma Pvt } \\
\text { Ltd }\end{array}$ & 17.02 .2019 & 21.12 .2021 & F - B \\
\hline & Calpol 500 & GlaxoSmithKline & 10.08 .2019 & 21.11 .2021 & F - C \\
\hline & Pyrigesic 500 & East India Pharma & 18.08 .2019 & 19.11 .2021 & F - D \\
\hline
\end{tabular}

\section{Methodology:}

\section{Preparation of Phosphate buffer at pH 7.4 [7]:}

Dissolve $27.218 \mathrm{~g}$ of potassium di-hydrogen phosphate and $7.99 \mathrm{~g}$ of sodium hydroxide in sufficient distilled water containing in the $1000 \mathrm{ml}$ volumetric flask and to make up to the volume $1000 \mathrm{ml}$.

Place $50 \mathrm{ml}$ of $0.2 \mathrm{M}$ Potassium di-hydrogen phosphate in a $200 \mathrm{ml}$ volumetric flask, add the specified volume of $0.2 \mathrm{M}$ sodium hydroxide and then add distilled water to make up the volume $200 \mathrm{ml}$.

\section{Preparation of calibration curve of paracetamol [8]:}

Stock solution of drug $(1 \mathrm{mg} / \mathrm{ml})$ is prepared by dissolving $100 \mathrm{mg}$ of drug in $100 \mathrm{ml}$ solution of phosphate buffer $\mathrm{pH}$ $7.4 \mathrm{in} 100 \mathrm{ml}$ volumetric flask (to get $1000 \mu \mathrm{g} / \mathrm{ml} \mathrm{drug}$ solutions) with vigorous shaking. A aliquot sample $(10 \mathrm{ml})$ from previous stock is diluted to $100 \mathrm{ml}$ with phosphate buffer $\mathrm{pH} 7.4$ to get a stock solution to get a concentration of $100 \mu \mathrm{g} / \mathrm{ml}$ of drug. The stock solution was filtered through Whatmann filter paper No.41. The respective samples at the range of $.1 \mathrm{ml}$ to $1 \mathrm{ml}$ was taken in each test tube separately and diluted with phosphate buffer pH 7.4 to make the total volume upto $10 \mathrm{ml}$ to make a concentration range 1 to 10 $\mathrm{mcg} / \mathrm{ml}$. The standard solutions for the drug having concentration $1,2,3,4,5,6,7,8,9$ and $10 \mu \mathrm{g} / \mathrm{ml}$ was prepared with phosphate buffer $\mathrm{pH} 7.4$ from the stock solution. A calibration curve was plotted between absorbance $\mathrm{v} / \mathrm{s}$ concentration to get the linearity and regression equation.

\section{In vitro dissolution study ${ }^{[8]}$ :}

Dissolution rate studies were performed in $900 \mathrm{ml}$ of phosphate buffer at ph 7.4 at $37 \pm 0.5{ }^{\circ} \mathrm{C}$, using 6-station USP type-II (paddle) apparatus with paddle rotating at $50 \mathrm{rpm}$. Different marketed $500 \mathrm{mg}$ of Paracetamol tablet was placed in dissolution basket. At fixed time intervals, samples withdrawn were filtered and spectrophotometrically analysed for the drug content at $268 \mathrm{~nm}$. The rate of drug release at different time interval was calculated and the kinetics of drug release was analysed according the different kinetics models like zero order, first order, higuchi model etc.

\section{RESULT AND DISCUSSION:}

A UV absorption maximum was determined by scanning $10 \mu \mathrm{g} / \mathrm{ml}$ solution of paracetamol in phosphate buffer 7.4, in between 200-400 nm by using UV-visible spectrophotometer. Further a representative spectrum was drawn of paracetamol in phosphate buffer pH 7.4. The absorbance of solutions of pure paracetamol drug were measured at $268 \lambda$ max shown in table 2 and a calibration curve was plotted with the regression value 0.999 shown in Fig. 2. The obtained regression value was indicating about the linearity between the concentration (Conc.) and absorbance (Abs.) 
Table 2: Absorption profile of paracetamol

\begin{tabular}{|c|c|}
\hline Conc. $(\mathbf{m c g} / \mathbf{m l})$ & Abs. \\
\hline 1 & 0.06 \\
\hline 2 & 0.108 \\
\hline 3 & 0.164 \\
\hline 4 & 0.219 \\
\hline 5 & 0.285 \\
\hline 6 & 0.33 \\
\hline 7 & 0.39 \\
\hline 8 & 0.455 \\
\hline 9 & 0.510 \\
\hline 10 & 0.555 \\
\hline
\end{tabular}

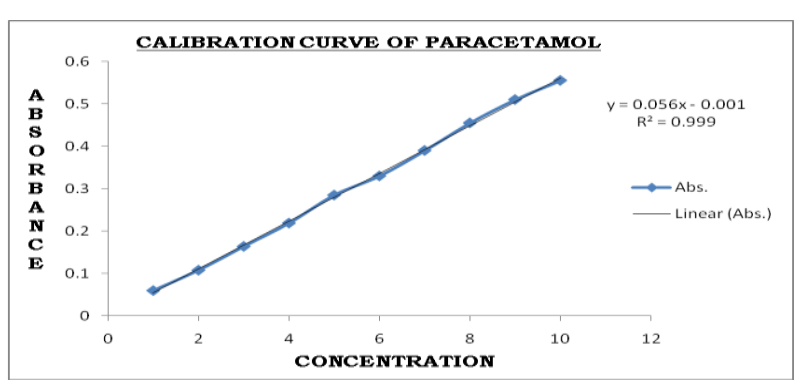

Fig. 2 : Calibration curve of paracetamol using phosphate buffer at 7.4

\section{In-Vitro release study:}

The in vitro dissolution studies of the marketed paracetamol tablets was carried out using USP type II apparatus (Electrolab, Mumbai, India) at 50rpm. The dissolution medium consisted of $900 \mathrm{ml}$ of distilled water maintained at $37 \pm 0.5^{\circ} \mathrm{C}$. The drug release at different time intervals was measured using an UV visible spectrophotometer.

The dissolution rate was subjected to various mathematical models like zero order given in Table 3 , first order given in Table 4, Higuchi model given in Table 5 and Krosmeyer Peppas model given in Table 6 and to elucidate the kinetics behaviour and mechanism of drug release from the different marketed tablets, data obtained from the release studies were fitted to various models shown in Fig. 3 to Fig. 6 . The comparative evaluation of in vitro dissolution qualities of various paracetamol tablets was done by contrasting the values of regression coefficient given in table 7 . After evaluating all of the data, it has been concluded that among all of the formulation, apart from $\mathrm{F}-\mathrm{A}$ and $\mathrm{F}-\mathrm{E}$ batch, all other batches was showing better regression coefficient. It was observed from the regression coefficient values that the release kinetics of' paracetamol from all the tablets appears to be almost uniform.

Table 3: Drug release data fitted to Zero order model

\begin{tabular}{|c|c|c|c|c|c|}
\cline { 2 - 6 } \multicolumn{1}{c|}{} & \multicolumn{5}{c|}{ Cumulative \% drug release } \\
\hline Time (min) & F - A & F - B & F - C & F - D & F - E \\
\hline 5 & 41.98 & 16.51 & 9.9 & 37.32 & 39.63 \\
\hline 10 & 42.644 & 25.451 & 29.391 & 41.944 & 40.624 \\
\hline 20 & 46.615 & 28.072 & 34.353 & 44.594 & 41.944 \\
\hline 30 & 49.584 & 32.033 & 36.003 & 49.214 & 46.574 \\
\hline 45 & 54.544 & 32.033 & 36.334 & 53.175 & 48.554 \\
\hline 60 & 61.815 & 43.603 & 37.984 & 58.135 & 50.865 \\
\hline 75 & 65.126 & 43.934 & 39.964 & 61.206 & 55.165 \\
\hline 90 & 69.096 & 47.864 & 40.154 & 63.746 & 58.796 \\
\hline
\end{tabular}

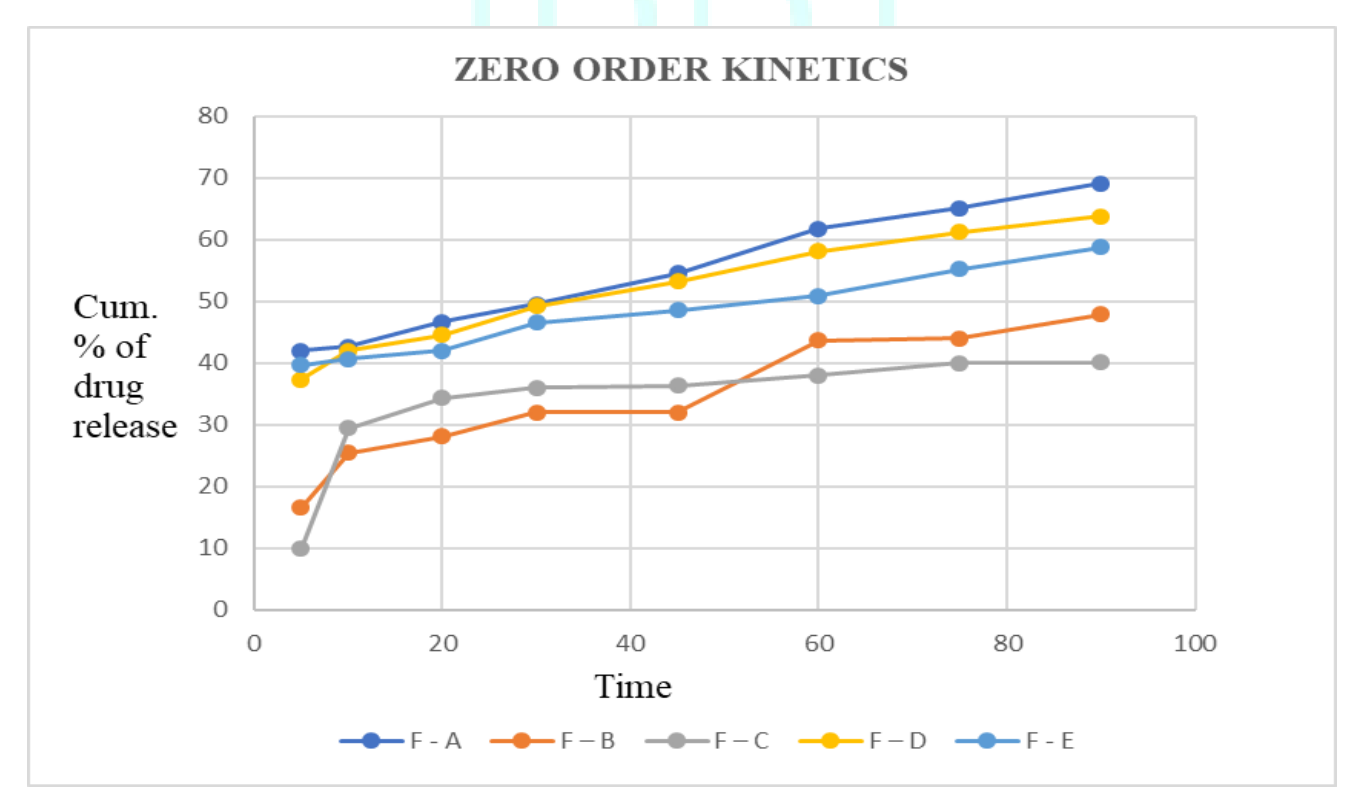

Fig. 3: Comparative zero order kinetics of different marketed paracetamol tablet 
Table 4: Drug release data fitted to First order model

\begin{tabular}{|c|c|c|c|c|c|}
\cline { 2 - 6 } \multicolumn{1}{c|}{} & \multicolumn{5}{c|}{ Log cumulative \% of drug retained } \\
\hline Time (min) & F - A & F - B & F - C & F - D & F - E \\
\hline 5 & 1.763 & 1.921 & 1.958 & 1.797 & 1.78 \\
\hline 10 & 1.758 & 1.872 & 1.848 & 1.763 & 1.773 \\
\hline 20 & 1.727 & 1.856 & 1.817 & 1.743 & 1.763 \\
\hline 30 & 1.702 & 1.832 & 1.806 & 1.705 & 1.727 \\
\hline 45 & 1.657 & 1.832 & 1.803 & 1.67 & 1.711 \\
\hline 60 & 1.581 & 1.751 & 1.792 & 1.621 & 1.691 \\
\hline 75 & 1.542 & 1.748 & 1.778 & 1.588 & 1.651 \\
\hline 90 & 1.49 & 1.717 & 1.777 & 1.559 & 1.614 \\
\hline
\end{tabular}

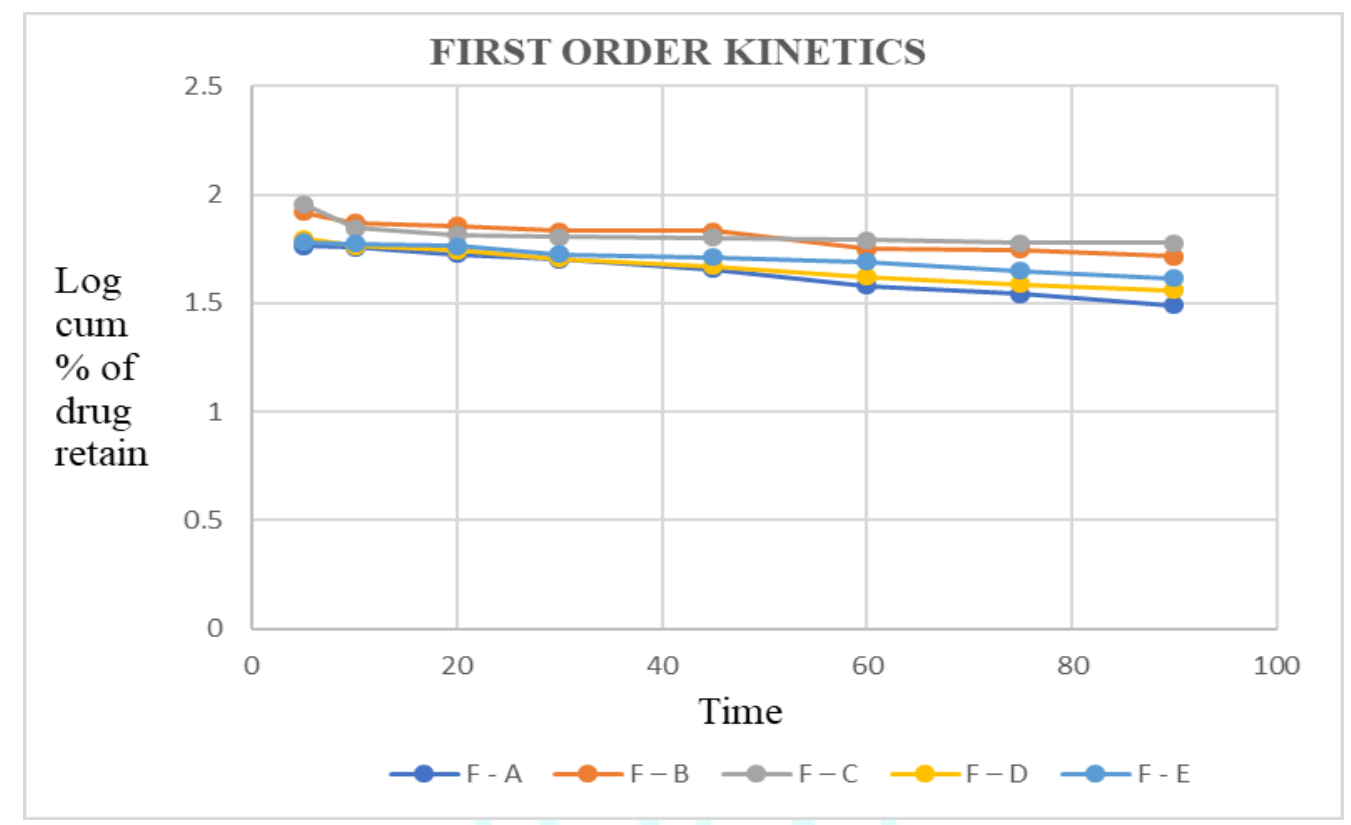

Fig. 4: Comparative First order kinetics of different marketed paracetamol tablet

Table 5: Drug release data fitted to Higuchi model

\begin{tabular}{|c|c|c|c|c|c|}
\cline { 2 - 6 } \multicolumn{1}{c|}{} & \multicolumn{5}{c|}{ Cumulative \% of drug release } \\
\hline Square root of time & F - A & F - B & F - C & F - D & F - E \\
\hline 2.236 & 41.98 & 16.51 & 9.9 & 37.32 & 39.63 \\
\hline 3.162 & 42.644 & 25.451 & 29.391 & 41.944 & 40.624 \\
\hline 4.472 & 46.615 & 28.072 & 34.353 & 44.594 & 41.944 \\
\hline 5.477 & 49.584 & 32.033 & 36.003 & 49.214 & 46.574 \\
\hline 6.708 & 54.544 & 32.033 & 36.334 & 53.175 & 48.554 \\
\hline 7.745 & 61.815 & 43.603 & 37.984 & 58.135 & 50.865 \\
\hline 8.66 & 65.126 & 43.934 & 39.964 & 61.206 & 55.165 \\
\hline 9.486 & 69.096 & 47.864 & 40.154 & 63.746 & 58.796 \\
\hline
\end{tabular}




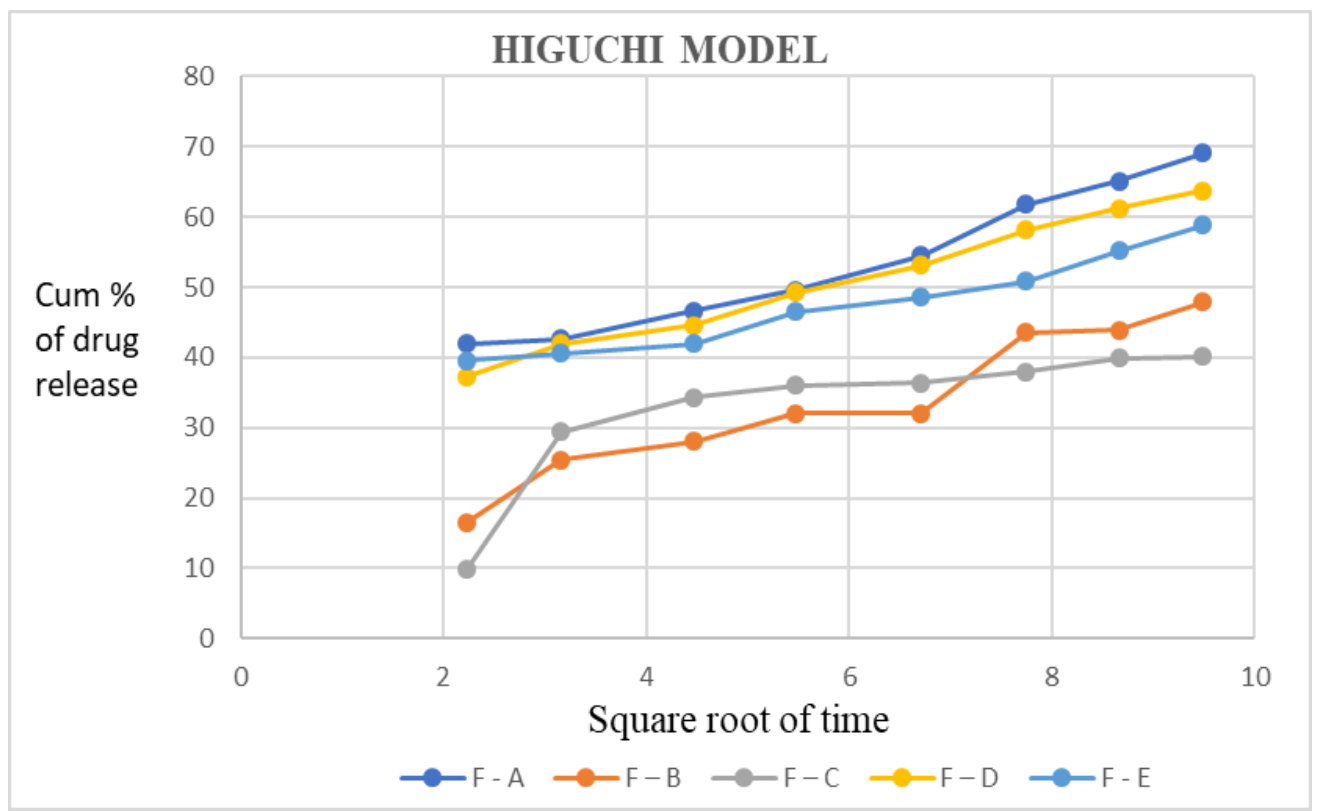

Fig. 5: Comparative Higuchi kinetics of different marketed paracetamol tablet

Table 6: Drug release data fitted to Krosmeyer peppas model

\begin{tabular}{|c|c|c|c|c|c|}
\cline { 2 - 6 } \multicolumn{1}{c|}{} & \multicolumn{5}{c|}{ Log cumulative \% of drug release } \\
\hline Log time (min) & F - A & F - B & F - C & F - D & F - E \\
\hline 0.698 & 1.623 & 1.217 & 0.99 & 1.571 & 1.598 \\
\hline 1 & 1.629 & 1.405 & 1.468 & 1.622 & 1.608 \\
\hline 1.301 & 1.668 & 1.448 & 1.535 & 1.649 & 1.622 \\
\hline 1.477 & 1.695 & 1.505 & 1.556 & 1.692 & 1.668 \\
\hline 1.653 & 1.736 & 1.505 & 1.56 & 1.725 & 1.686 \\
\hline 1.778 & 1.791 & 1.639 & 1.579 & 1.764 & 1.706 \\
\hline 1.875 & 1.813 & 1.642 & 1.601 & 1.786 & 1.741 \\
\hline 1.954 & 1.839 & 1.68 & 1.603 & 1.804 & 1.769 \\
\hline
\end{tabular}

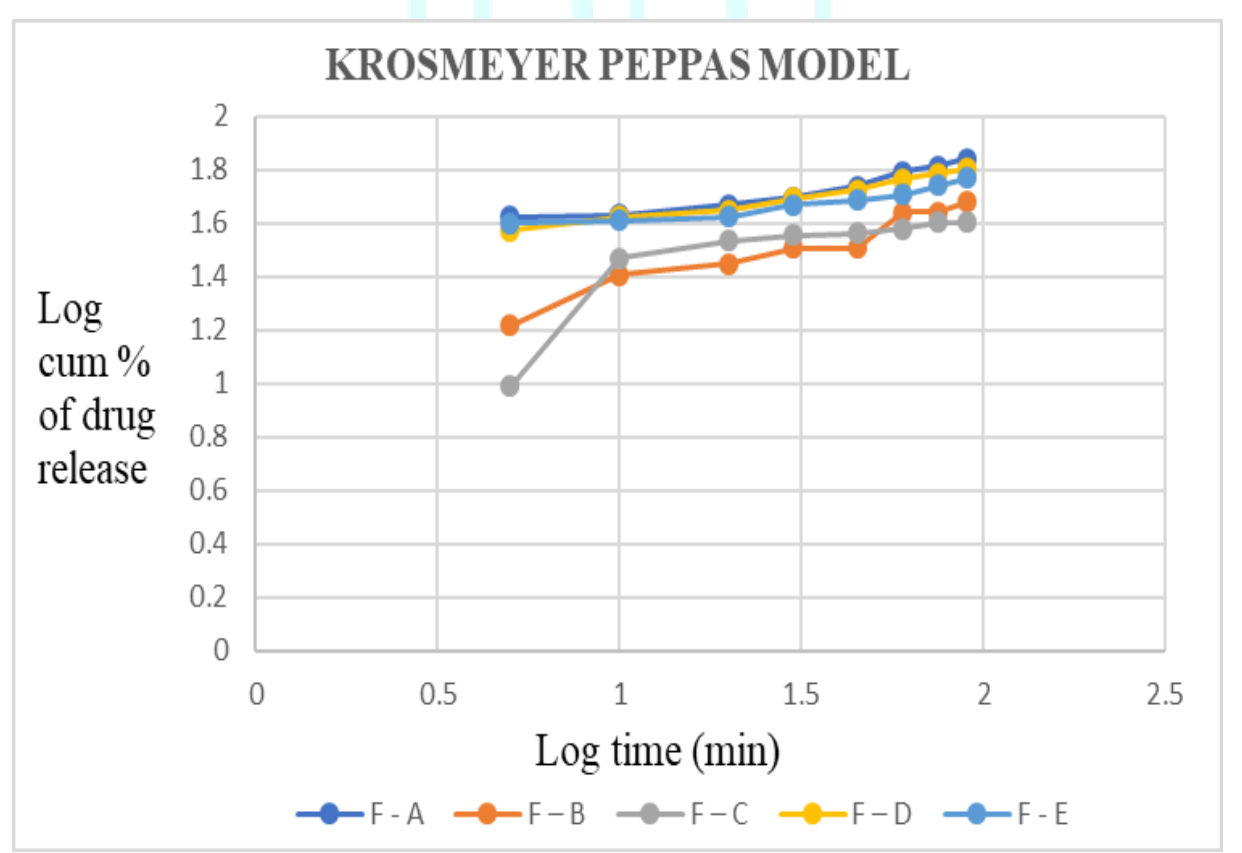

Fig. 6: Comparative Krosmeyer peppas kinetics of different marketed paracetamol tablet 
Table 7: Comparison of regression coefficient of different kinetics model

\begin{tabular}{|c|c|c|c|c|}
\hline Batch Code & Zero order & First order & Higuchi model & $\begin{array}{c}\text { Krosmeyer peppas } \\
\text { model }\end{array}$ \\
\hline F - A & 0.972 & $0 . .573$ & 0.969 & 0.903 \\
\hline F - B & 0.993 & 0.938 & 0.995 & 0.975 \\
\hline F - C & 0.988 & 0.994 & 0.960 & 0.892 \\
\hline F - D & 0.920 & 0.989 & 0.945 & 0.994 \\
\hline F - E & 0.532 & 0.991 & 0.664 & 0.692 \\
\hline
\end{tabular}

\section{CONCLUSION:}

Bioavailability and absorption of drug is dependent on dissolution profile. A dissolution study gives an idea about the amount of drug available for absorption after oral administration. In the present study, the release of paracetamol from all tablets, specially $\mathrm{F}-\mathrm{C}$ batch (Crocin 500 ) was followed sustained release; though the drug release in 60 mints were almost about $60 \%$ which meets BP Specifications.

\section{REFERENCES:}

1. Qureshi M S, Rukh G, Kirplani P D, Farheen A, Hamid M. A comparative study of quality on conventional paracetamol tablets available in Pakistan. Research in Pharmacy and Health Sciences, 2016; 2(3): 205 - 210.

2. Sowjanya S P, Madhavi C H, Sowjanya D, Girisha D, Deeraj D, Vidya D S. Formulation and enhancement of dissolution rate of paracetamol tablets employing selected binders and disintegrants as per 22 factorial design. Indian Journal of Pharmaceutical Science \& Research, 2016; 6(2): 73 -77.
3. Sultana R, Sarker K and Sultana S. Preparation and evaluation of paracetamol effervescent tablets under normal and exaggerated storage conditions. Bangladesh Pharmaceutical Journal, 2014; 17(1): 75 - 78.

4. Aulton M E. Aulton's Pharmaceutics : The Design and manufacture of Medicines, 2nd edition, Churchill livingstone, 1987.

5. Ghayas S, Sheraz M A, Anjum F, Baig M T. Factors influencing the dissolution testing of drugs. Pakistan Journal of Health Research, 2013; 1(1): 1 - 11.

6. The Indian Pharmacopoeia, Government of India, Ministry of health and family welfare, Controller of publication, New delhi, vol. II, 1996, A80 - A84.

7. Ahmida N H S, Abu - Naja M S, Doghman Y S A. Determination of paracetamol in tablet by Different Spectrophotometric Method. Asian Journal of Chemistry, 2009; 21(3): 2233 - 2240.

8. Kumar C S P, Ratna J V, Aditya P, Raakhiya SK, Sunitha S V, Revathi S. Formulation and evaluation of fast dissolving tablets of paracetamol using oats powder. International Journal of Pharmaceutical Science Invention, 2016; 5(3):7 12. 